\title{
Histiocitosis Dendrocítica (Histiocitosis de Células de Langerhans), Manifestaciones Orales y Craneofaciales. Reporte de Tres Casos
}

\author{
Dendrocitic Histiocytosis (Langerhans Cell Histiocytosis), \\ Oral and Craniofacial Manifestations. Report of Three Cases
}

Oriana Valenzuela Rivera*; Juan José Cortés Santander*; María Angélica Vila Valenzuela** \& Roxana Parra Lara***

VAlenzUela, R. O.; CORTÉS, S. J. J.; VILA, V. M. A. \& PARRA, L. R. Histiocitosis dendrocítica (Histiocitosis de células de Langerhans), manifestaciones orales y craneofaciales. Reporte de tres casos. Int. J. Morphol., 31(3):1137-1145, 2013.

RESUMEN: La Histiocitosis de células de Langerhans (HCL) corresponde a una proliferación anormal de células dendríticas, de tipo clonal, cuyo espectro clínico general incluye compromiso de la piel y las mucosas, las uñas, el hueso, la médula ósea, el hígado, el bazo, linfonodos, el pulmón, el tracto gastrointestinal inferior, el sistema endocrino y el sistema nervioso central. En este trabajo presentamos tres casos de la enfermedad, con manifestaciones orales y craneofaciales, analizadas desde el punto de vista clínico (examen extra e intra oral), imagenológico (tomografías computadas) e histopatológico (expresión de marcador específico CD1a). Dos casos fueron clasificados como HCL de presentación aguda diseminada y uno como presentación crónica. Los pacientes fueron tratados oportunamente con quimioterapia según el protocolo del Programa Infantil Nacional de Drogas Antineoplásicas.

PALABRAS CLAVE: Histiocitosis; Células de Langerhans; Hand-Schüller-Christian; Letterer-Siwe; Hashimoto-Pritzker.

\section{INTRODUCCIÓN}

La Histiocitosis de células de Langerhans (HCL), antes llamada Histiocitosis X o enfermedad de células de Langerhans, corresponde a una proliferación anormal de células dendríticas, de tipo clonal, cuyo espectro clínico general incluye compromiso de la piel y las mucosas, las uñas, el hueso, la médula ósea, el hígado, el bazo, los linfonodos, el pulmón, el tracto gastrointestinal inferior, el sistema endocrino y el sistema nervioso central. Afecta principalmente a niños y adultos jóvenes y las manifestaciones más comunes son alteraciones óseas y lesiones en piel y mucosas (Toro et al., 2009). En este trabajo presentamos tres casos de la enfermedad, con manifestaciones orales y craneofaciales, analizadas desde el punto de vista clínico, imagenológico e inmunohistoquímico.

\section{REPORTES DE CASOS}

Caso 1. Lactante sexo masculino de nueve meses de edad, hijo de padres adolescentes sanos, con antecedente familiar de linfoma. La ficha clínica del paciente registra antecedentes de reiterados procesos infecciosos, siendo la primera hospitalización inmediata al nacimiento debido a una infección ocular. En ese momento presentó además piodermitis y abscesos inguinales, sospechándose inmunodeficiencia. En control luego de dos semanas presentó vesículas con pus seca en forma de costra en ambos pliegues inguinales, zona retroauricular y zona supraciliar. Después de un período de 5 días de haber remitido, las lesiones vuelven a observarse, extendiéndose además a ambos oídos diagnosticándose otitis purulenta. A la semana siguiente presenta lesiones orales con pus y mal olor asociado a inflamación, con sangramiento gingival en zonas de erupción dentaria. Se diagnostica posible hendidura palatina. Es derivado por Odontopediatra para estudio radiográfico periapical, para evaluación de erupción dentaria, asociada a sangramiento gingival.

Examen clínico. a) Examen extraoral: se observó aumento de volumen de consistencia media, fluctuante en proceso frontal del maxilar derecho, exoftalmo bilateral, piel seca y

* Facultad de Medicina y Odontología, Universidad de Antofagasta, Antofagasta, Chile.

** Clínica Altazor, Antofagasta, Chile.

**** Unidad de Anatomía Patológica, Hospital Regional Antofagasta, Antofagasta, Chile. 
en la zona supraciliar se observan pequeñas vesículas secas, b) Examen intraoral: se observó aumento de volumen de tejido blando de aspecto esponjoso - granulomatoso de la región del paladar duro y encías las que presentaban una coloración rojo - violácea con presencia de zonas hemorrágicas, se observó la erupción prematura de los dientes temporales, los que se disponían en forma atípica fuera de la curva del arco dentario (Fig. 1A). Los dientes se encontraban depresibles, "flotantes".

Se sospecha Histiocitosis de células de Langerhans y se indica evaluación inmediata con tomografía computada a modo de evaluar compromiso y extensión.

Exámenes imagenológicos. Se realizó tomografía computada de macizo craneofacial observándose extenso compromiso óseo por infiltración de tejido blando, se extendía desde el proceso frontal del maxilar derecho, cuerpo maxilar, piso orbitario y pared medial de la órbita ipsilateral (Fig. 1B y 1C). En maxilar izquierdo la invasión por partes blandas se extendía hacia posterior invadiendo cuerpo del esfenoides, fosa orbitaria posterior, fosa media y senos etmoidales izquierdos (Fig. 1D). En la calota y mandíbula se observaron múltiples imágenes en sacabocado y erosivas (Fig. 1E). Los dientes se encontraban sin sustento óseo, los dientes temporales $5.3,5.4,5.5,6.3,6.4,6.5,7.3,7.4,7.5,8.3,8.4$ y 8.5 se encontraban sin desarrollo radicular, dando el característico aspecto de estar suspendidos en tejido blando, dientes "flotantes" (Fig. 1F). Los dientes 5.2 y 6.2 se encuentran desplazados hacia palatino. Se observo pérdida de la pared alveolar vestibular de los dientes 5.1 y 6.1. Se descartó hendidura palatina.

En tomografía de cuello se observaron adenopatías cervicales izquierdas. No se observó compromiso visceral en tomografía abdominal.

Estudio inmunohistoquímico de las muestras. Se realizó estudio inmunohistoquímico a muestra de piel y de hueso, el que reveló positividad a S-100. Las muestras además resultaron positivas para el anticuerpo específico CD1a (Fig. $2 \mathrm{~A}$ y $2 \mathrm{~B})$.

Con los antecedentes clínicos, imagenológicos e histopatológicos se confirma el diagnóstico de Histiocitosis de células de Langerhans.
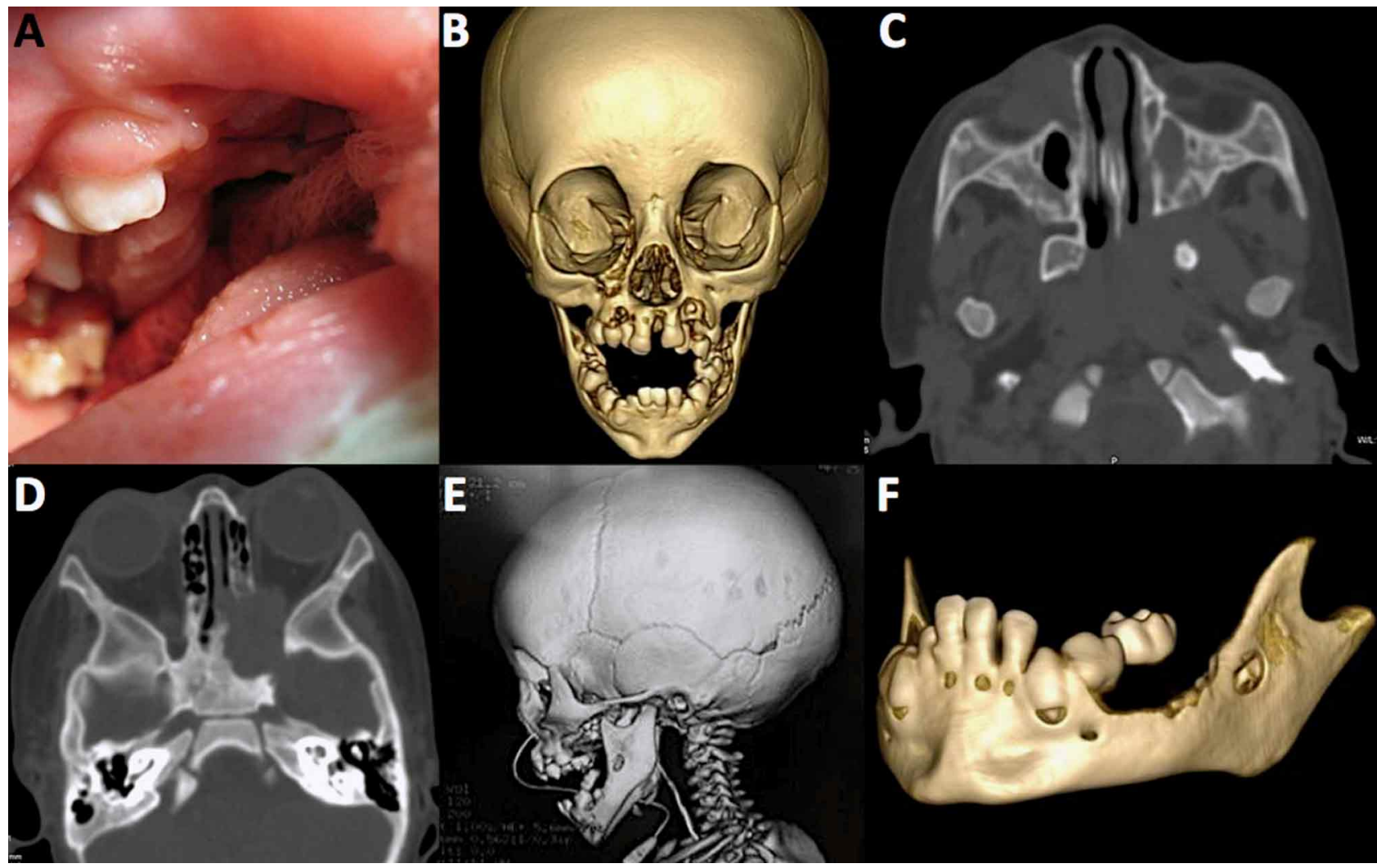

F

Fig. 1. A) Mal posición de piezas dentarias. B) Compromiso proceso frontal de maxilar derecho (TC Reconstrucción 3-D). C) Compromiso por partes blandas de proceso frontal maxilar derecho (TC axial). D) Pared posterior orbita y celdillas etmoidales izquierdas comprometidas (TC axial). E) Imágenes en sacabocado calota y mandíbula (TC 3-D). F) Pérdida de sustento oseo "dientes flotantes" lado izquierdo (TC Reconstrucción 3-D). 


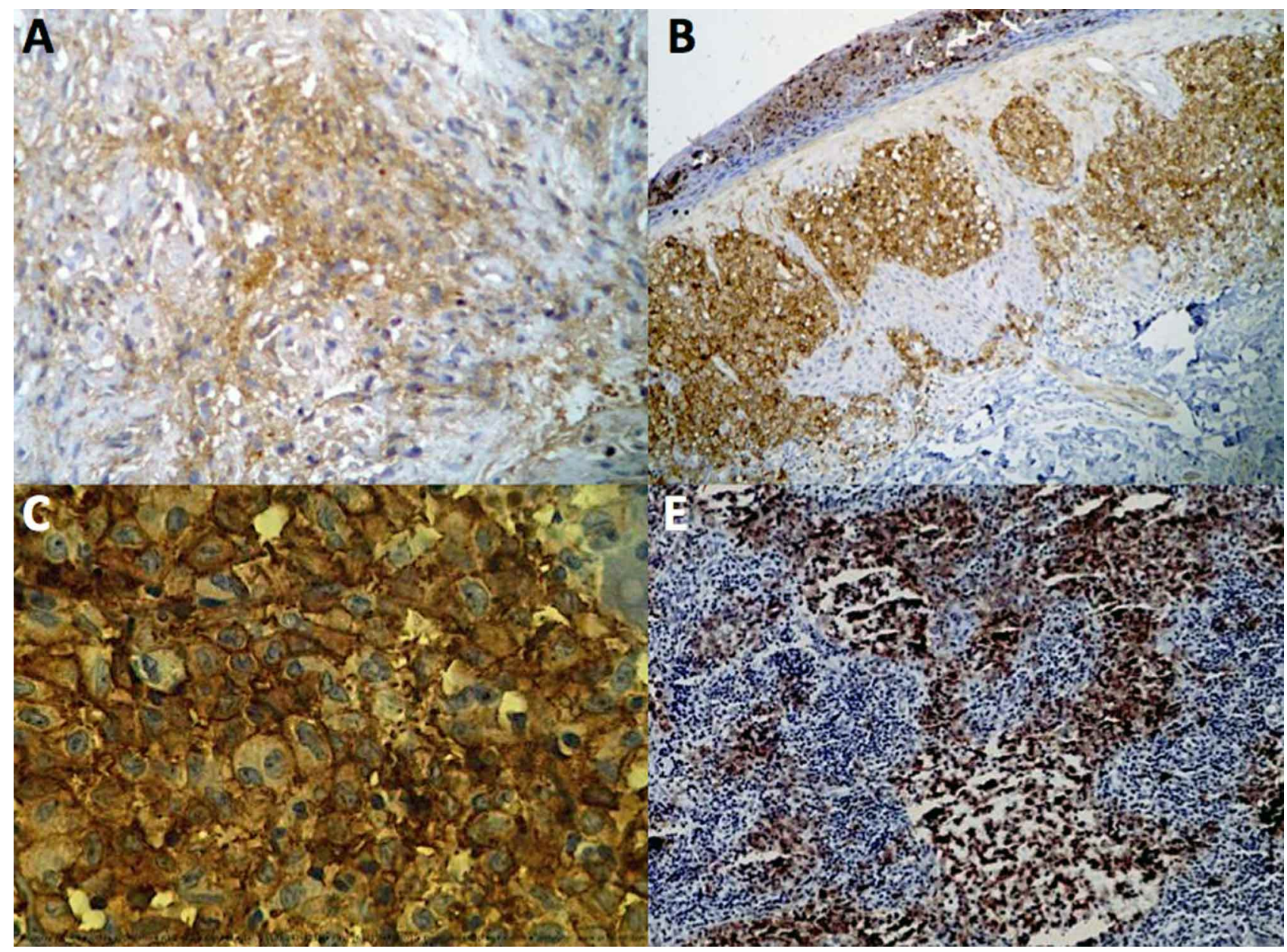

Fig. 2. A) Reacción positiva para CD1a en muestra de hueso para caso 1 (Inmunohistoquímica, DAB, 20x). B) Reacción positiva para CD1a en muestra de piel para caso 1 (Inmunohistoquímica, DAB, 4x).C) Positividad intensa para S100 en muestra de hueso para caso 2 (Inmunohistoquímica, DAB, 20x). D) Reacción positiva para CD1a en muestra de hueso para caso 2 (Inmunohistoquímica, DAB, 10x).

Tratamiento. Se indicó quimioterapia según Protocolo Nacional PINDA la que se inició en el Hospital Luis Calvo Mackenna de Santiago, prosiguiendo el protocolo en la Unidad de Oncología Infantil del Hospital Regional de Antofagasta, indicándose controles de salud oral en la Unidad de Odontopediatría del mismo establecimiento. El control de la pérdida de espacio se realizó con ortodoncista del extrasistema, orientando el tratamiento al mantenimiento de los espacios producto de la pérdida prematura de piezas dentarias, tanto por la enfermedad como por el tratamiento quirúrgico (curetaje) de los maxilares que junto con eliminar tejido granulomatoso infiltrado, eliminó gérmenes dentarios inmersos en la lesión. Actualmente se encuentra en etapa de rehabilitación en espera de un tratamiento definitivo para la restitución de las piezas dentarias perdidas, desarrollo de los maxilares y recuperación de la salud del Sistema estomatognático.

Caso 2. Niña de cuatro años 6 meses de edad, quién es derivada por su pediatra para estudio imagenológico con diag- nóstico de proceso infeccioso de la región mandibular derecha, que no cede al tratamiento antibiótico. La paciente presenta hipercalciuria idiopática. La niña es hija de padres sanos, y no presenta antecedentes dermatológicos.

Examen clínico. a) examen extraoral se observó aumento de volumen mandibular derecho de consistencia dura, que compromete cuerpo y rama mandibular, piel de aspecto normal, b) examen intraoral se observó aumento de volumen duro de fondo del vestíbulo a nivel de dientes $8.4-8.5$, la mucosa se observó de coloración rosado pálida, los dientes se encontraban sanos, alineados en el arco dentario, sin movilidad (Fig. 3A).

Exámenes imagenológicos. Se realizó tomografía computada de región mandibular observándose extensa lesión que comprometía rama y cuerpo mandibular derecho de aspecto lítico con infiltración de tejido blando (Fig. 3B y 3C), en relación a dientes 4.6 - 4.7 el saco dentario se observó infil- 


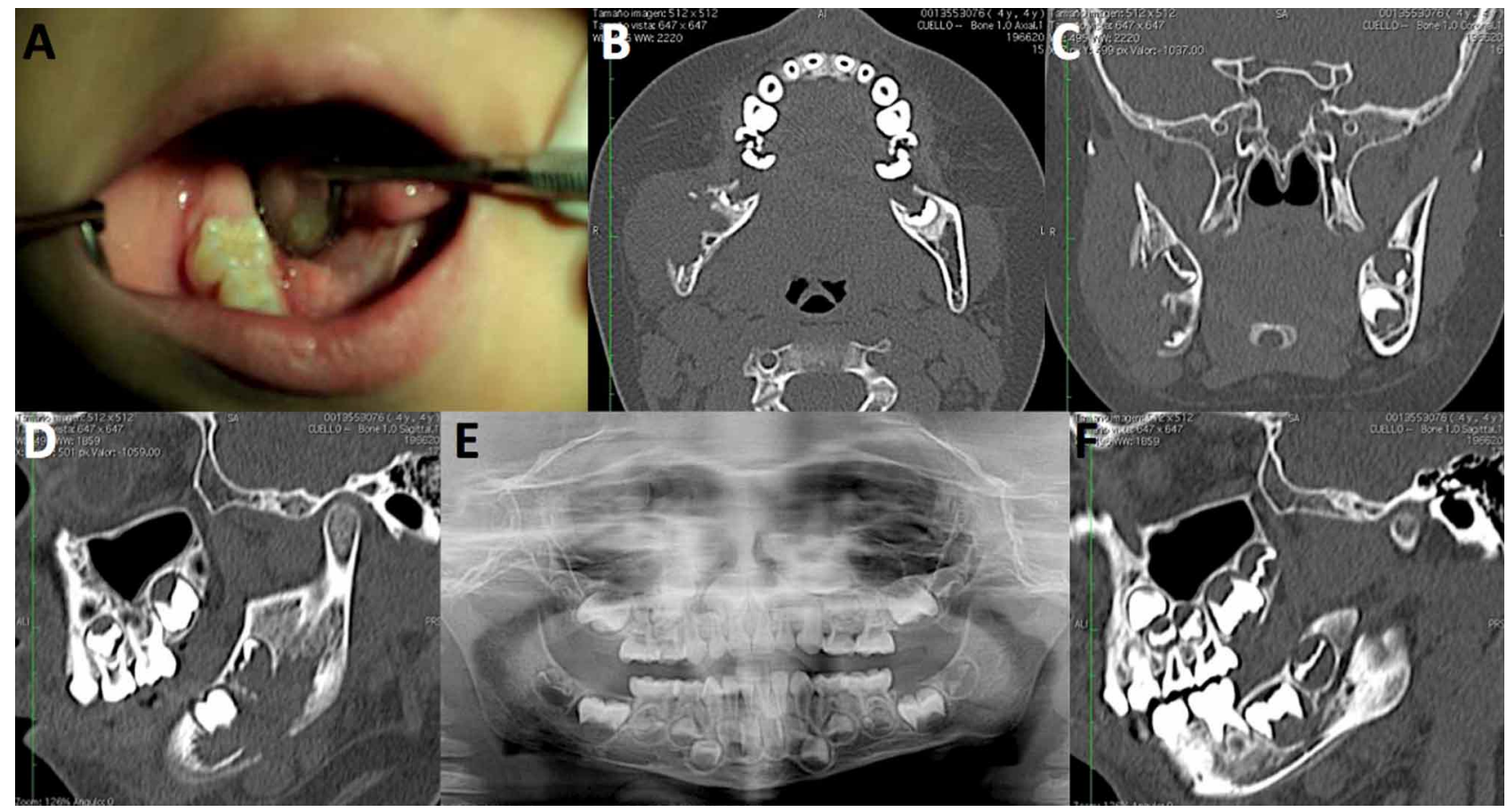

Fig. 3. A) Dientes 8.4 - 8.5 sanos, mucosa aspecto normal. B) Lesión aspecto lítico cuerpo y rama mandibular (TC Axial). C) Lesión aspecto lítico cuerpo y rama mandibular (TC coronal). D) Lesión aspecto lítico cuerpo y rama mandibular, infiltración sacos dentarios dientes 4-6, 4-7 (TC sagital). E) Infiltración sacos dentarios dientes 4.6 - 4.7 (Radiografía Panorámica). F) Infiltración canal mandibular derecho (TC sagital).

trado, dilatado respecto a dientes homólogos izquierdos (Fig. 3D y 3E). El canal mandibular se observó infiltrado por la lesión (Fig. 3F). A la inyección de medio de contraste se observó realce intralesional.

En la tomografía de cuello se reveló la presencia de adenopatías cervicales derechas en cadena yugular. Se descarta viseromegalia.

Estudio inmunohistoquímico de las muestras. El estudio de inmunohistoquímica reveló positividad a S- 100 y CD1a (Fig 2C y 2D). Con los antecedentes clínicos, imagenológicos e histopatológicos se confirmó el diagnóstico de Histiocitosis de células de Langerhans.

Tratamiento. Se indicó quimioterapia según Protocolo LCH III 2002 PINDA 2002, la que se inicia en el Hospital Luis Calvo Mackenna de Santiago, prosiguiendo el tratamiento en la Unidad de Oncología Infantil del Hospital Regional de Antofagasta. La paciente mantiene controles odontológicos periódicos y evaluación radiográfica intra y extraoral.

Caso 3. Se presenta el caso de un niño de un año 8 meses de edad, hijo de padres sanos, quién fue hospitalizado por cuadro de 3 semanas de evolución caracterizado por aumento de volumen de la región mandibular derecha, piel de aspec- to normal, afebril. El pediatra solicitó tomografía computarizada para evaluar compromiso y extensión de la lesión. El paciente ha presentado dermatitis del pañal.

Examen clínico. a) Examen extraoral: se observó aumento de volumen mandibular derecho de consistencia dura, que comprometía cuerpo y rama mandibular, asociado a lesión de partes blandas, piel de aspecto normal. b) Examen intraoral: se observó aumento de volumen de mediana dureza de fondo del vestíbulo a nivel de dientes $8.4-8.5$, la mucosa ligeramente eritematosa, dientes sanos, normalmente dispuestos en el arco dentario, sin movilidad (Fig. 4A).

Exámenes imagenológicos. Se realizó tomografía computada de región mandibular observándose extensa lesión que comprometía rama y cuerpo mandibular derecho de aspecto lítico, pérdida de cortical vestibular con infiltración de tejido blando, en relación a diente 8.5 (Fig. 4B y 4C). El diente 8.5 se ha movilizado hacia el reborde alveolar, comparado con su homólogo izquierdo, 7.5 (Fig. 4D y 4E). La lesión comprometía al canal mandibular (Fig. 4-F). La tomografía no reveló presencia de adenopatías cervicales. Se descarta viseromegalia.

Estudio inmunohistoquímico de las muestras. El estudio de inmunohistoquímica reveló positividad a S-100 y CD1a. 


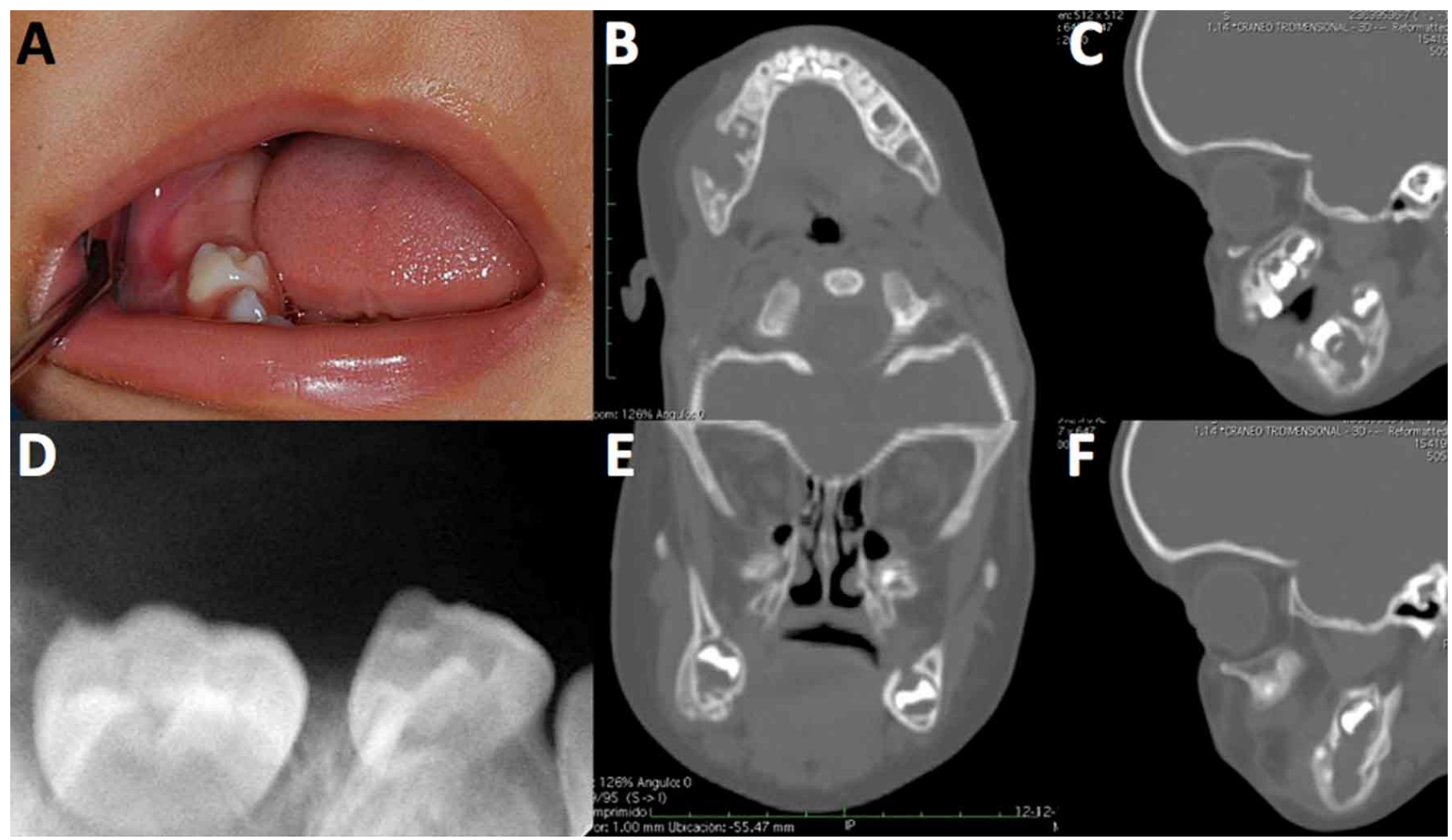

Fig. 4. A) Mucosa ligeramente edematosa, dientes sanos. B) Infiltración cuerpo mandibular, pérdida de cortical vestibular (TC axial). C) Infiltración de cuerpo mandibular y diente 8.5 (TC sagital). D) Diente 8.5 en relación a reborde alveolar sin desarrollo radicular (Radiografía retroalveolar). E) Diente 8.5 próximo a reborde alveolar (TC coronal). F) Infiltración de canal mandibular derecho (TC sagital).

Con los antecedentes clínicos, imagenológicos e histopatológicos se confirmó el diagnóstico de Histiocitosis de células de Langerhans.

Tratamiento. Se indica quimioterapia según Protocolo PINDA, la que se inicia en el Hospital Luis Calvo Mackenna de Santiago, prosiguiendo el tratamiento en la Unidad de Oncología Infantil del Hospital Regional de Antofagasta.

\section{DISCUSIÓN}

Las células de Langerhans fueron descritas por primera vez en el año 1847 por Paul Langerhans (Markku, 2003; Curtis \& Darin, 2008). Su principal función es presentar antígenos para linfocitos $\mathrm{T}$ y se encuentran en el estrato suprabasal de la epidermis y en la dermis, membranas mucosas incluyendo la superficie ocular, linfonodos timo, bazo y tejido óseo (Saap et al., 2005; Neville et al., 2002; Cawson \& Odell, 2009). Corresponden a alrededor de 4-5\% de las células epidermales y tienen la capacidad de migrar por la vía linfática a la región paracortical de los linfonodos donde interactúan con las células $\mathrm{T}$ como parte de la respuesta inmune (Mckee et al., 2005).
La célula de Langerhans se conoce como célula dendrítica porque desde su citoplasma se extienden brazos que se contactan simultáneamente con varias células adyacentes, están relacionadas con células veladas, interdigitaciones dendríticas, células dendríticas intersticiales, células dendríticas foliculares y células dendríticas tímicas, tienen limitada capacidad fagocítica, su principal función es iniciar el contacto con antígenos para procesarlos y presentarlos a las células $\mathrm{T}$, tiene un rol principal en las etapas tempranas de la respuesta de las células $\mathrm{T}$, inmunidad celular y un rol indirecto en la inmunidad humoral (Neville et al.; Markku).

En las alteraciones óseas, endocrino-metabólicas, se produce una sustitución del hueso por tejido granulomatoso del sistema retículo-endotelial (Boraks, 2004; Nakamura et al., 2005). Afectan con mayor frecuencia a cráneo, costillas, vértebras y mandíbula, ésta última se encuentra comprometida en un 73 - 75\% de los casos y se presentan usualmente en la zona posterior del cuerpo mandibular. Se ven afectados el proceso mastoides, lo que simula una mastoiditis infecciosa y la extensión al oído medio causa sordera por la destrucción de los huesecillos (Montero et al., 2002; Neville et al.; Regezi et al., 2003; Mumbuc et al., 2006; Cawson \& Odell; Madrigal-Martínez-Pereda et al., 2009). Las lesio- 
nes óseas de los maxilares pueden presentarse como lesiones únicas ó múltiples del hueso alveolar o basal, en algunas oportunidades la pérdida ósea puede ser diagnosticada clínicamente como periodontitis severa, caracterizada por su avance rápido, destructivo, con pérdida prematuras de los dientes involucrados en la lesión, es común observar movilidad dentaria, odontalgia, pérdida de tejido óseo alveolar, dando la característica imagen de "dientes flotantes" (De Freitas et al., 2002; Sollecito et al., 2005; Jalil \& Hin-Lau, 2009; Madrigal-Martínez-Pereda et al.). El compromiso de la mandíbula se acompaña de inflamación gingival, los antes mencionados "dientes flotantes" y dolor por afectación de la rama mandibular y compromiso del nervio facial. Pocos casos reportan afección del proceso condilar de la mandíbula. A nivel de la mucosa oral ésta se ve afectada observándose inflamación, sangramiento, proliferación y/o ulceración (Neville et al.; Madrigal-MartínezPereda et al.).

La Histiocitosis de células de Langerhans, se presenta con mayor frecuencia en niños y adultos jóvenes, siendo cerca de la mitad de los casos reportados en la literatura menores de 10 años. Afecta con mayor frecuencia al sexo masculino (Stull et al., 1992; Montero et al.). En la serie de Nicholson et al. (1998) se encontró una relación de 2:1 entre hombres y mujeres.

En relación a la etiología y patogenia de la enfermedad, éstas se desconocen. Se proponen factores genéticos (Freundlich et al., 1972; Shala et al., 2004; Eckardt \& Schultze, 2003), infecciosos, inmunológicos (Som \& Curtin, 2004; Montero et al.; Stull et al.; Petridis et al., 2004) y virales (Stull et al.; Larralde et al., 2008; Cawson \& Odell), sugiriéndose que el virus Epstein-Barr tendría un rol en la fisiopatología de la enfermedad (Nicollas et al., 2010). Se postula que la alta concentración de citoquinas relacionada con la HCL podría causar un bloqueo de la respuesta inmune en la etapa de transición de respuesta innata a la adaptativa (Toro et al.). La relación de la HCL con el sistema inmune influye en la severidad de la enfermedad, como es el caso de los pacientes de temprana edad, cuyo sistema inmune es inmaduro (Stull et al.; Hefti \& Jundt, 1995).

Clásicamente la Sociedad Internacional del Histiocito (Histiocyte Society) clasifica las Histiocitosis en tres grandes grupos: Histiocitosis tipo I o histiocitosis de células de Langerhans (HCL), Histiocitosis tipo II: Histiocitosis de fagocitos mononucleares distintos a las células de Langerhans y Histiocitosis tipo III: Histiocitosis malignas.

Podemos clasificar tipos de HCL en función del grado de compromiso que éstos presentan. Es ésta clasificación según extensión, a la que se tiende en la actualidad: a) Presentación crónica, focal o localizada. Se denomina granuloma eosinófilo y cursa como una lesión benigna, localmente infiltrativa que afecta generalmente a adultos. Compromete la piel en el 10\% de los casos y al tejido óseo aproximadamente en un $80 \%$ de los casos (Cawson \& Odell; Boraks). Puede presentarse en cualquier hueso siendo los sitios más frecuentes pelvis, costillas, cráneo, huesos largos, vértebras y maxilares, las lesiones pueden ser solitarias o múltiples, sin compromiso visceral (Cawson \& Odell). Cuando se presentan en los maxilares, la mandíbula se ve afectada en un 63\% y los maxilares en un 37\% (Pedemonte et al., 2005), en estas lesiones se observa destrucción del tejido periodontal, con una imagen radiográfica de "dientes flotantes", lo que puede confundirse con una periodontitis juvenil. Se encuentra generalmente restringido a 2 ó 3 dientes contiguos, los que se encuentran depresibles y desplazados (Cawson \& Odell; Boraks; Betts \& McNeish, 1972). En los exámenes imagenológicos es posible observar en la calota craneana lesiones osteolíticas de contornos regulares (Stull et al.; Boraks). Se considera de buen pronóstico (Toro et al.).

b) Presentación crónica diseminada. Se designa como la Enfermedad de Hand-Schüller-Christian, también denominada HCL crónica diseminada y afecta principalmente a niños de más de seis años de edad. Compromete la piel en un 30\% de los casos, visceras y presenta lesiones óseas que se distribuyen en los maxilares, cráneo, miembros inferiores (Neville et al.; Boraks). Puede observarse linfadenopatías y esplenomegalia moderadas. Se observa exoftalmos y diabetes insípida, ésta última dada por el compromiso hipofisiario por la alteración de la silla turca y hueso esfenoides, constituyendo la triada característica de la enfermedad (Stull et al.; Hefti \& Jundt; Sollecito et al.; Quiñones et al., 2004). Esta enfermedad posee una tasa de mortalidad menor al 50\% (Toro et al.).

c) Presentación aguda diseminada. Constituye la Enfermedad de Letterer-Siwe que compromete piel en un $90 \%$ a 100\% de los casos, visceras, linfonodos y tejido óseo. Se presenta en niños pequeños y lactantes (Neville et al.; Som \& Curtin; Pedemonte et al.), afectando a menores de hasta 3 años. Es de progreso rápido y posee una tasa de mortalidad de 50-66\% debido al compromiso multiorgánico (Som \& Curtin; Boraks; Toro et al.). Algunos autores consideran esta forma aguda de HCL, como una manifestación aguda de linfoma (Saap et al.), ya que tiene un comportamiento similar a un Linfoma de células de Langerhans (Cawson \& Odell). En este caso la literatura no reporta predilección de sexo. Los pacientes desarrollan infecciones bacterianas como otitis media, mastoiditis y linfoadenitis (Stull et al.; Martínez et al., 1993; Menaches et al., 1998; Quraishi et al., 1993). Las manifestaciones 
orales de la Enfermedad de Letterer-Siwe son poco frecuentes, éstas pueden ser inflamaciones gingivales, necrosis, candidiasis, erupción prematura de los dientes y en ocasiones éstos erupcionan en posición ectópica (Betts \& McNeish; George \& Yogirajan, 2001). Los casos 2 y 3, presentados en este trabajo corresponderían a esta clasificación, sin embargo no se observó compromiso visceral en ninguno de los pacientes estudiados.

d) Presentación congénita. Llamada Enfermedad de Hashimoto-Pritzker. Se presenta al nacer y se caracteriza por afecciones cutáneas en un 100\% de los casos (Toro et $a l$. .). El curso de la enfermedad puede ser la resolución espontánea en un período de tres a cuatro meses, o evolucionar a la forma sistémica (Enjolras et al., 1992; Larralde et al.; Sankilampi et al., 2008). Muchas de las lesiones cutáneas nos pueden orientar hacia la presencia de HCL como por ejemplo una dermatitis del pañal de características crónicas, dermatitis seborreica de cuero cabelludo y zona retroauricular, vesículas y pápulas que suelen erosionarse originando costras y/o ulceraciones, además de adenopatías regionales asociadas a las lesiones de la piel (Larralde $e t$ al.). El caso 1 analizado en este estudio correspondería a esta clasificación, destacándose las importantes afecciones cutáneas reportadas desde el nacimiento.

Desde el punto de vista histopatológico la presencia de gránulos citoplasmáticos de Birbek, a la microscopía electrónica, además de la concentración de polimorfonucleares eosinófilos, permite diferenciar inflamaciones periapicales y periodontales de HCL. Además, es posible observar infiltrado inflamatorio crónico, como células plasmáticas, linfocitos y células mononucleares (Quiñones et al.). En el análisis inmunohistoquímico, las células de Langerhans expresan proteína S-100, vimentina, E-Caderina y ICAM-1, además de una variedad de antígenos propios de leucocitos y macrófagos como el complejo mayor de histocompatibilidad (CHM) clase I y II, CD1a, CD1b, CD18, CD29, CD45 y CD4, de los cuales se considera al marcador CD1a el más específico (McKee et al.).
El tratamiento de la enfermedad varía de acuerdo a los órganos afectados. Cuando se encuentran comprometidos maxilares y mandíbula generalmente el tratamiento es en base a curetaje, excisión de las lesiones, en los casos de mayor compromiso óseo se indica la radioterapia o quimioterapia, dado el potencial de transformación maligna de la enfermedad (Eckardt \& Schultze). En este contexto, los tres casos presentados en este trabajo fueron tratados con quimioterapia de acuerdo al protocolo PINDA (Programa Infantil Nacional de Drogas Antineoplásicas). En el caso de lesiones óseas localizadas se ha reportado la efectividad de la inyección intralesional de corticoides (Neville et al.; Sartoris \& Parker, 1984). La regresión espontánea de la enfermedad es poco frecuente (Neville et al.), sin embargo se reportan casos de regresión espontánea de lesiones del lóbulo temporal en un paciente con HCL multisistémica (Gunny et al., 2004; Stull et al.).

El pronóstico de la enfermedad es variable, dependiendo de la edad del paciente, la primera manifestación y el número de órganos involucrados (Schultze et al., 1999; Eckardt \& Schultze), generalmente el pronóstico es bueno cuando sólo se ve afectado el tejido óseo sin compromiso visceral, como es el caso de los tres pacientes aquí analizados. Cuando la HCL afecta a menores de dos años, las expectativas de vida son inciertas, sin embargo el diagnóstico oportuno y un tratamiento precoz auguran buenos resultados y mayor sobrevida para estos pacientes (Neville et al.).

Es importante comentar, que en ocasiones se superponen hallazgos clínicos especialmente en niños de alrededor de 3 años que presentan características tanto del Síndrome de Hand-Schüller-Christian, como la Enfermedad de Letterer-Siwe a los que Rewald en 1960 denominó LettererChristian's disease (Schajowicz \& Slullitel, 1973).

La evaluación multidisciplinaria y su rápida derivación permite la detección precoz y diagnóstico oportuno de la enfermedad; esto fue el factor principal del curso favorable y control de la Histiocitosis de células de Langerhans en nuestros pacientes.

VALENZUELA, R. O.; CORTÉS, S. J. J.; VILA, V. M. A. \& PARRA, L. R. Dendrocitic histiocytosis (Langerhans cell histiocytosis), oral and craniofacial manifestations. Report of three cases. Int. J. Morphol., 31(3):1137-1145, 2013.

SUMMARY: The Langerhans cell histiocytosis ( $\mathrm{LCH}$ ) corresponds to an abnormal proliferation of dendritic cells, clonal type, which usually involves compromise of skin and mucous membranes, nails, bone, bone marrow, liver, spleen, lymph nodes, lung, lower gastrointestinal tract, endocrine system and the central nervous system. We present three cases of the disease, with oral and craniofacial manifestations, analyzed from the clinical perspective (intra and extra oral exam), imaging (CT scans) and histopathological (specific marker CD1a expression). Two cases were classified as acute disseminated LCH presentation and one as a chronic disease. Patients were treated with chemotherapy timely according to the protocol of the National Child Program of Antineoplastic Drugs.

KEY WORDS: Histiocytosis; Langerhans cell; Hand-Schüller-Christian; Letterer-Siwe; Hashimoto-Pritzker. 


\section{REFERENCIAS BIBLIOGRAFICAS}

Betts, P. R. \& McNeish, A. S. Oral manifestations of LettererSiwe disease. Arch. Dis. Child., 47(253):463-4, 1972.

Boraks, S. Diagnóstico bucal. $2^{\text {a }}$ ed. São Paulo, Artes Médicas, 2004.

Cawson, R. A. \& Odell, E. Fundamentos de Medicina y Patología Oral. $8^{\text {a }}$ ed. Edinburgh, Elsevier Churchill Livingstone, 2009.

Curtis, E. \& Darin, R. Langerhans Cell Histiocytosis. Surv. Ophthalmol., 53(4):332-58, 2008.

De Freitas, A.; Rosa, J. E. \& Souza, I. F. Radiología Odontológica. São Paulo, Artes Médicas Latinoamérica, 2002.

Eckardt, A. \& Schultze, A. Maxillofacial manifestations of Langerhans cell histiocytosis: a clinical and therapeutic analysis of 10 patients. Oral Oncol., 39(7):687-94, 2003.

Enjolras, O.; Leibowitch, M.; Bonacini, F.; Vacher-Lavenu, M. C. \& Escande, J. P. Congenital cutaneous Langerhans histiocytosis, apropos 7 cases. Ann. Dermatol. Venereol., 119(2):111-7,1992.

Freundlich, E.; Amit, S.; Montag, Y.; Suprun, H. \& Nevo, S. Familial ocurrence of Letterer - Siwe Disease. Arch. Dis. Child., 47(251):122-5, 1972.

George, A. E. \& Yogirajan, K. Letterer siwe disease. Indian J. Dematol. Venereol. Leprol., 67:334-5, 2001.

Gunny. R.; Clifton, A. \& Al-Memar, A. Spontaneous regression of supretentorial intracerebral Langerhans`cell histiocytosis. Br. J. Radiol., 77(920):685-7, 2004.

Hefti, F. \& Jundt, G. Langerhans cell histiocytosis. Ortophade, 24(1):73-81, 1995.

Jalil, Ab. \& Hin-Lau, S. Oral Langerhans cell histiocytosis in Malaysian children: a 40-year experience. Int. J. Paediatr. Dent., 19(5):349-53, 2009.

Larralde, M.; Abad, M. E. \& Gomar, B. Histiocitosis de células de Langerhans en menores de un año. Arch. Argent. Pediatr., 106(3):269-72, 2008

Madrigal-Martínez-Pereda, C.; Guerrero-Rodríguez, V.; Guisado-Moya, B. \& Meniz-García, C. Langerhans cell histiocytosis: literature review and descriptive analysis of oral manifestations. Med. Oral Patol. Oral Cir. Bucal, 14(5):E222-8, 2009.

Markku, M. Diagnostic soft tissue pathology. New York, Churchill Livingstone, 2003.
Martínez, R.; Villas, C.; Barrios, R. H.; Sierra L. \& Beguiristain, J. L. Histiocytosis X. Rev. Med. Univ. Navarra, 38(2):41-7, 1993.

Mckee, P. H; Calonje, E. \& Granter, S. R. Histiocytic disorders. In: Pathology of the skin with clinical correlations. 3rd ed. Philadelphia, Elsevier Mosby, 2005.

Menaches, M. I.; Burgos, A.; Sancho, M.; Gras, J. R. \& Marco, P. Langerhans cell histiocytosis. Report of four cases. Acta Otorrinolaringol. Esp., 49(3):237-40, 1998.

Montero, S.; Reyes, M.; Basili, A. \& Castellón M. Granuloma eosinófilo de la mandíbula: Reporte de dos casos clínicos. Rev. Dent. Chile, 93(3):10-2, 2002.

Mumbuc, S.; Karatas, E.; Durucu, C.; Kanlıkama, M.; Sirikci, A.; Bakır, K. \& Deniz, H. A rare disorder mimics otitis media in children: Langerhans cells histiocytosis. Int. J. Pediatr. Otorhinolaryngol. Extra, 1(1):68-71, 2006.

Nakamura, S.; Bessho, K.; Nakao, K.; Iizuka, T. \& Scott, R. F. Langerhans Cell Histiocytosis confined to jaw. J. Oral Maxillofac. Surg., 63(7):989-95, 2005.

Neville, B.; Damm, D.; Allen, C. \& Bouquot, J. Oral \& Maxillofacial Pathology. $2^{\text {nd }}$ ed. Philadelphia, W. B. Saunders, 2002.

Nicholson, H. S.; Egeler, R. M. \& Nesbit M. E. The Epidemiology of Langerhans Cell Histiocytosis. Hematol. Oncol. Clin. North Am., 12(2):379-84, 1998.

Nicollas, R.; Rome, A.; Belaïch, H.; Roman, S.; Volk, M.; Gentet, J. C.; Michel, G. \& Triglia, J. M. Head and neck manifestation and prognosis of Langerhans cell histiocytosis in children. Int. J. Pediatr. Otorhinolaryngol., 74(6):669-73, 2010.

Pedemonte, C. A.; Rojas, R. A. \& Romo, L. Histiocitosis de Células de Langerhans Crónica Focal (Granuloma Eosinófilo).Reporte de un caso. Acta Odontol. Venez., 43(2):146-50, 2005.

Petridis, A. N.; Giannopoulos, T. L.; Anastasiadou, K.; Sidiropoulou, M. S. \& Palladas, P. Solitary Langerhans cell histiocytosis of the orbital wall. Eur. J. Radiol. Extra, 51(3):957, 2004

Quiñones, L.; Ampuero, E. \& Argandoña, J. Histiocitosis de Células de Langerhans aguda diseminada (Enfermedad de Letterer -Siwe): Reporte de caso clínico. Rev. Dent. Chile, 95(3):1922,2004

Quraishi, M. S.; Blayney, A. W. \& Breatnach, F. Aural symptoms as primary presentation of Langerhan's cell histiocytosis. Clin. Otolaryngol. Allied Sci., 18(4):317-23, 1993. 
VALENZUELA, R. O.; CORTÉS, S. J. J.; VILA, V. M. A. \& PARRA, L. R. Histiocitosis dendrocítica (Histiocitosis de células de Langerhans), manifestaciones orales y craneofaciales. Reporte de tres casos. Int. J. Morphol., 31(3):1137-1145, 2013.

Regezi, J. A.; Sciubba, J. J. \& Jordan, R. C. K. Oral Pathology: Clinical Pathologic Correlations. $4^{\text {th }}$ ed. Philadelphia, W. B. Saunders, 2003.

Saap, J.; Eversole, L. \& Wysocki, G. Patología Oral y Maxilofacial Contemporánea. $2^{\mathrm{a}}$ ed. Madrid, Elsevier, 2005.

Sankilampi, U.; Huikko-Tarvainen, S.; Kärjä, V.; Pirinen, E.; Naukkarinen, A. \& Hollmén, A. Congenital Langerhans cell histiocytosis mimicking a "blueberry muffin baby". $J$. Pediatr. Hematol Oncol., 30(3):245-8, 2008.

Sartoris, D. J. \& Parker, B. R. Histiocytosis X: Rate Pattern of Resolution of Osseous Lesions. Radiology, 152(3):679-84, 1984.

Schajowicz, F. \& Slullitel, J. Eosinophilic granuloma of bone and its relationship to Hand-Schiiller-Christian and LettererSiwe syndromes. J. Bone Joint Surg., 55B(3):545-65, 1973.

Schultze, A.; Eckardt, A. \& Kuske, M. Oral manifestations of Langerhans`cell histiocytosis. Therapeutic strategies involving oral and maxillofacial surgery. Mund Kiefer Gesichtschir., 3(3):158-64, 1999.

Shahla, A.; Parvaneh, V. \& Hossein, H. D. Langerhans cells histiocytosis in one family. Pediatr. Hematol. Oncol., 21(4):313-20, 2004.

Sollecito, T. P.; Sullivan, K.; Pinto, A.; Stewart, J. \& Korostoff, J. Condiciones sistémicas asociadas con periodontitis en la infancia y la adolescencia. Una revisión de las posibilidades diagnósticas. Med. Oral Patol. Oral Cir. Bucal, 10(2):142-50, 2005.

Som, P. \& Curtin, H. Head and Neck imaging. $4^{\text {th }}$ ed. St. Louis, Mosby, 2004.

Stull, M.; Kransdorf, M. \& Devaney, K. Langerhans Cell Histiocytosis of Bone. Radiographics, 12:801-23, 1992.

Toro, A. M.; Restrepo, R. \& Ochoa, A. Histiocitosis de células de Langerhans. Rev. Asoc. Col. Dermatol., 17(1):34-44, 2009.
Dirección para Correspondencia:

Dra. Oriana Valenzuela Rivera

Universidad de Antofagasta

Facultad de Medicina y Odontología

Casilla 70, Antofagasta

CHILE

Email: draoriana@gmail.com

Recibido : 18-01-2013

Aceptado: 22-06-2013 